\title{
Depauperate avifauna in tropical peat swamp forests following logging and conversion to oil palm agriculture: evidence from mist-netting data
}

\begin{abstract}
Increased demand for oil palms has led to a massive expansion of logging and conversion of peat swamp forests in Southeast Asia. Although palm oil is a primary driver of economic growth, the unsustainable expansion of the oil palm industry has led to the widespread degradation of peat swamp forests. Birds have been studied to determine their responses to landscape changes in the North Selangor Peat Swamp Forest (NSPSF). We captured 1045 birds from 72 species of the NSPSF and 168 individual birds from 13 species in oil palm plantations using mist-netting. Our results show that peat swamp forest supports more bird species than the oil palm areas. Non-metric Multidimensional Scaling revealed that both vegetation types had an influence on bird species composition. SIMPER analysis also showed that the percentage of the assemblage similarity within the oil palm areas was $51.30 \%$, while it was $31.32 \%$ in the peat swamp. We found that the populations of frugivores, insectivores, and omnivores were significantly higher in the peat swamp forest, whereas there was no significant difference in the granivores between the two sites. To conserve peat swamp forests, stakeholders should implement habitat restoration, maintain landscape connectivity, and retain a forest area network.
\end{abstract}

Keyword: Peat swamp; Oil palm; Avian diversity; Feeding guilds; Logging 